Correction

\title{
Correction: Liu et al. Microstructure and Properties of SUS304 Stainless Steel Joints Brazed with Electrodeposited Ni-Cr-P Alloy Coatings. Materials 2021, 14, 4216
}

\author{
Shubin Liu ${ }^{1, *}$, Ikuo Shohji ${ }^{1}$, Tatsuya Kobayashi ${ }^{1}{ }^{\circledR}$, Katsuharu Osanai ${ }^{2}$, Tetsuya Ando ${ }^{2}$, Junichiro Hirohashi ${ }^{3}$, \\ Tsunehito Wake ${ }^{3}$, Katsufumi Inoue ${ }^{3}$ and Hiroki Yamamoto ${ }^{4}$ \\ 1 Graduate School of Science and Technology, Gunma University, 1-5-1, Tenjin-cho, Kiryu 376-8515, Japan; \\ shohji@gunma-u.ac.jp (I.S.); kobayashi.t@gunma-u.ac.jp (T.K.) \\ 2 Graduate School, Muroran Institute of Technology, 27-1, Mizumoto-cho, Muroran 050-8585, Japan; \\ 20042011@mmm.muroran-it.ac.jp (K.O.); ando@mmm.muroran-it.ac.jp (T.A.) \\ 3 Waki Factory Inc., 6-760 Higashi-sayamagaoka, Tokorozawa 359-1106, Japan; j-hirohashi@waki-ss.co.jp (J.H.); \\ t_wake@fc4.so-net.ne.jp (T.W.); k-inoue@waki-ss.co.jp (K.I.) \\ 4 Kandori Industry Co., 57-1 Kamimutsuguri Kanegasaki, Kota-cho 444-0123, Japan; kamiroku@kandori.jp \\ * Correspondence: t182b009@gunma-u.ac.jp
}

check for

updates

Citation: Liu, S.; Shohji, I.;

Kobayashi, T.; Osanai, K.; Ando, T.;

Hirohashi, J.; Wake, T.; Inoue, K.;

Yamamoto, H. Correction: Liu et al. Microstructure and Properties of SUS304 Stainless Steel Joints Brazed with Electrodeposited Ni-Cr-P Alloy Coatings. Materials 2021, 14, 4216. Materials 2021, 14, 5499. https:// doi.org/10.3390/ma14195499

Received: 6 September 2021 Accepted: 7 September 2021 Published: 23 September 2021

Publisher's Note: MDPI stays neutral with regard to jurisdictional claims in published maps and institutional affiliations.

Copyright: (c) 2021 by the authors. Licensee MDPI, Basel, Switzerland. This article is an open access article distributed under the terms and conditions of the Creative Commons Attribution (CC BY) license (https:// creativecommons.org/licenses/by/ $4.0 /)$.
Error in Figure/Table

In the original article [1], there was a mistake in "Figure 10. Spontaneous potentials of SUS304, brazed Ni-11P alloy coating, and brazed Ni-13.4Cr-11.6P alloy coating in $0.06 \mathrm{M} / \mathrm{L} \mathrm{NaCl}$ aqueous solution at different temperatures. Figure 11. Current density-time curve of galvanic couples of SUS304/brazed Ni-11P alloy coating and SUS304/brazed Ni-13.4Cr-11.6P alloy coating in $0.06 \mathrm{M} / \mathrm{L} \mathrm{NaCl}$ aqueous solution at different temperatures." as published. "The $80^{\circ} \mathrm{C}$ marked in Figures 10 and 11 should be changed to $60^{\circ} \mathrm{C}$. Add $\mathrm{NaCl}$ to the caption of Figure 11." The corrected "Figure 10. Spontaneous potentials of SUS304, brazed Ni-11P alloy coating, and brazed $\mathrm{Ni}-13.4 \mathrm{Cr}-11.6 \mathrm{P}$ alloy coating in $0.06 \mathrm{M} / \mathrm{L} \mathrm{NaCl}$ aqueous solution at different temperatures. Figure 11. Current density-time curve of galvanic couples of SUS304/brazed Ni-11P alloy coating and SUS304/brazed Ni-13.4Cr-11.6P alloy coating in $0.06 \mathrm{M} / \mathrm{L} \mathrm{NaCl}$ aqueous solution at different temperatures." appears below. The authors apologize for any inconvenience caused and state that the scientific conclusions are unaffected. The original article has been updated.

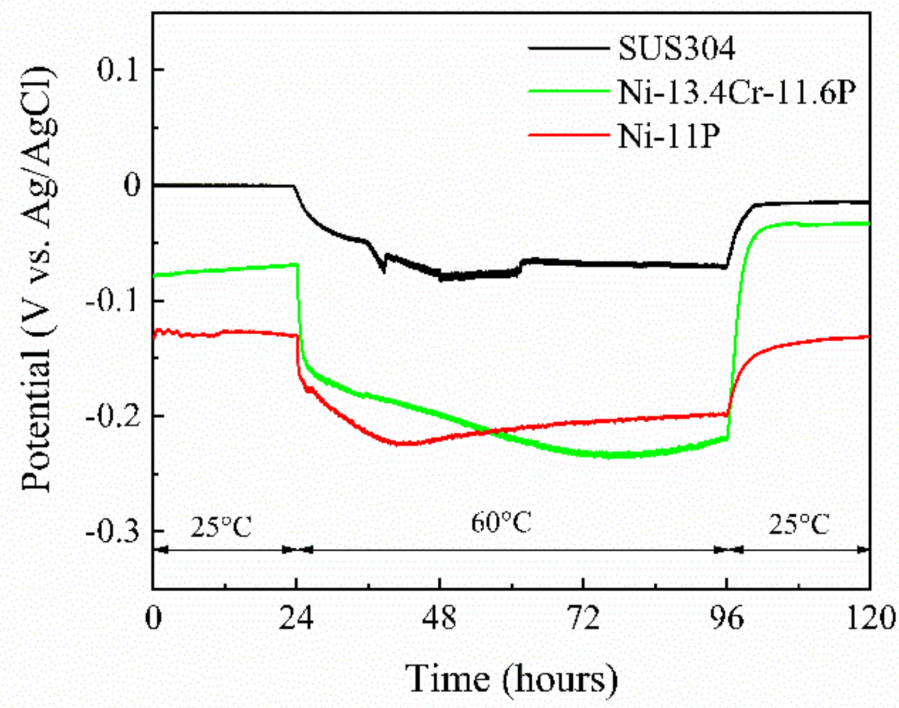

Figure 10. Spontaneous potentials of SUS304, brazed Ni-11P alloy coating, and brazed Ni-13.4Cr11.6P alloy coating in $0.06 \mathrm{M} / \mathrm{L} \mathrm{NaCl}$ aqueous solution at different temperatures. 


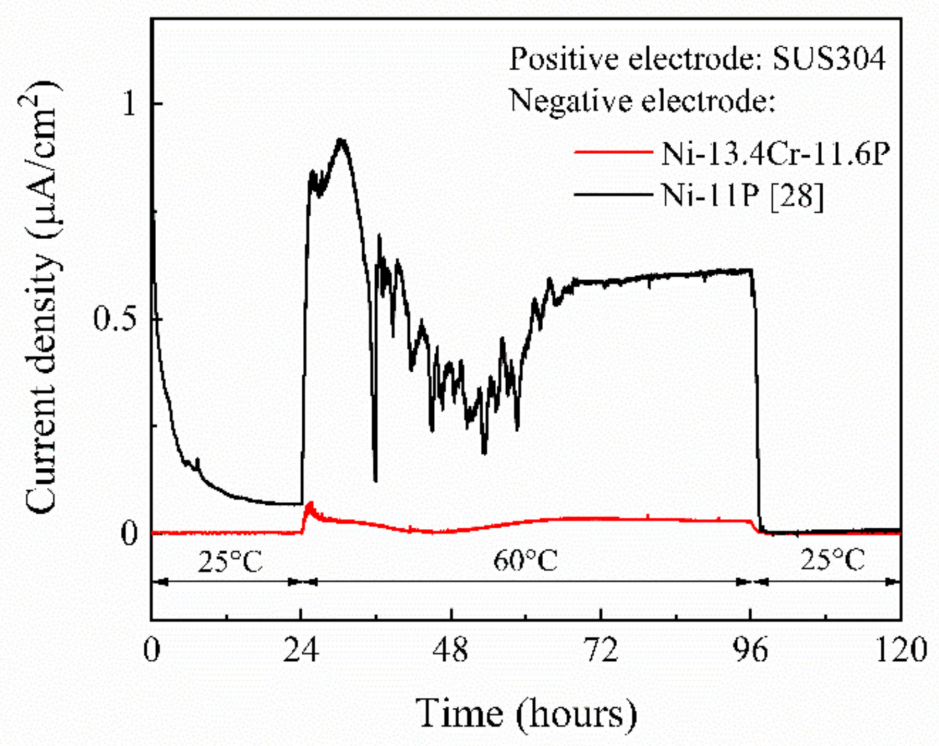

Figure 11. Current density-time curve of galvanic couples of SUS304/brazed Ni-11P alloy coating and SUS304/brazed Ni-13.4Cr-11.6P alloy coating in $0.06 \mathrm{M} / \mathrm{L} \mathrm{NaCl}$ aqueous solution at different temperatures.

\section{Text Correction}

There was an error in the original article. "The $80{ }^{\circ} \mathrm{C}$ in Section 2.5. Electrochemical Analysis and Section 3.5. Corrosion Behaviors should be changed to $60{ }^{\circ} \mathrm{C}^{\prime \prime}$.

A correction has been made to "Section 2. Materials and Methods and Section 3. Results and Discussion", "Section 2.5. Electrochemical Analysis and Section 3.5. Corrosion Behaviors", "Pages 5 of 14, 9 of 14, and 10 of 14":

"The spontaneous potential and galvanic current measurements were conducted in a $0.06 \mathrm{M} / \mathrm{L} \mathrm{NaCl}$ aqueous solution. For spontaneous potential measurement, a saturated silver chloride electrode $(\mathrm{Ag} / \mathrm{AgCl})$ was used as the reference electrode. The specimen and the reference electrode were set as positive and negative electrodes, respectively. The volume of the test solution was $200 \mathrm{~mL}$ and the distance between the two electrodes was set to $40 \mathrm{~mm}$. The measurement was initially performed at $25^{\circ} \mathrm{C}$ for $24 \mathrm{~h}$, then at $60{ }^{\circ} \mathrm{C}$ for $72 \mathrm{~h}$, and the solution temperature was subsequently restored to $25^{\circ} \mathrm{C}$ for $24 \mathrm{~h}$. For galvanic current measurement, the SUS304 plate and the specimen were set as positive and negative electrodes of a zero-shunt ammeter, respectively. The measurement was performed under the same temperature profile as for spontaneous potential measurement. The microstructure observation before and after the galvanic current measurement was conducted with the EPMA.

Figure 10 shows the spontaneous potentials of SUS304, brazed Ni-11P alloy coating, and brazed Ni-13.4Cr-11.6P alloy coating measured in a $0.06 \mathrm{M} / \mathrm{L} \mathrm{NaCl}$ solution. The spontaneous potentials of the brazed alloy coatings are more negative than that of SUS304 at different temperatures, indicating that the brazed alloy coatings are prone to become anode materials in the corrosion process, i.e., they are easily corroded. It is worth noting that the potentials of the three specimens shifted negatively as the temperature increased to $60{ }^{\circ} \mathrm{C}$. This phenomenon may be associated with the fact that the high temperature accelerates the destructive effect of $\mathrm{Cl}^{-}$ions on the oxide film on the surfaces of the specimens.

Figure 11 shows the current density-time curve of galvanic couples of SUS304/brazed Ni-11P alloy coating [28] and SUS304/brazed Ni-13.4Cr-11.6P alloy coating measured in a $0.06 \mathrm{M} / \mathrm{L} \mathrm{NaCl}$ solution. At a temperature of $25^{\circ} \mathrm{C}$, current scarcely flowed in both of the galvanic couples during the first $24 \mathrm{~h}$ of immersion. With the temperature increased to $60{ }^{\circ} \mathrm{C}$, a current density of up to $1.0 \mu \mathrm{A} / \mathrm{cm}^{2}$ flowed in the SUS304/brazed Ni-11P alloy coating galvanic couple, indicating that the brazed Ni-11P alloy coating was corroded. At the same temperature, only a current density of up to $0.07 \mu \mathrm{A} / \mathrm{cm}^{2}$ flowed in the 
SUS304/brazed Ni-13.4Cr-11.6P alloy coating galvanic couple, suggesting that the brazed $\mathrm{Ni}-13.4 \mathrm{Cr}-11.6 \mathrm{P}$ alloy coating has a better corrosion resistance than that of the brazed Ni-11P alloy coating. The current flow in the galvanic couples can be attributed to the increase in potential difference between SUS304 and the brazed alloy coatings at $60{ }^{\circ} \mathrm{C}$ (as shown in Figure 10), which acts as a driving force to promote the corrosion process [29]. When the temperature was restored to $25^{\circ} \mathrm{C}$, the current density of both galvanic couples dropped to approximately $0 \mu \mathrm{A} / \mathrm{cm}^{2}$.

The authors apologize for any inconvenience caused and state that the scientific conclusions are unaffected. The original article has been updated.

\section{Reference}

1. Liu, S.; Shohji, I.; Kobayashi, T.; Osanai, K.; Ando, T.; Hirohashi, J.; Wake, T.; Inoue, K.; Yamamoto, H. Microstructure and Properties of SUS304 Stainless Steel Joints Brazed with Electrodeposited Ni-Cr-P Alloy Coatings. Materials 2021, $14,4216$. [CrossRef] [PubMed] 